\title{
Relations between Serum Reactive Oxygen Metabolites (ROMs) and Various Inflammatory and Metabolic Parameters in a Japanese Population
}

\author{
Hiroshi Hirose ${ }^{1,2}$, Hiroshi Kawabe ${ }^{1,2}$, Naoko Komiya², and Ikuo Saito ${ }^{1,2}$ \\ ${ }^{1}$ Health Center, School of Medicine, Keio University, Tokyo, Japan \\ ${ }^{2}$ Department of Internal Medicine, School of Medicine, Keio University, Tokyo, Japan
}

\begin{abstract}
Aim: Both oxidative stress and inflammation are known to play roles in the pathogenesis of cardiovascular disease. We investigated the relations between reactive oxygen metabolites (ROMs) and various inflammatory and metabolic parameters in a Japanese population.

Methods: We analyzed 48 male and 69 female subjects, aged 25 to 65 years, who underwent an annual health checkup in our university. Serum ROM level was assayed using a free radical elective evaluator. We also measured serum concentrations of high-sensitivity C-reactive protein (hsCRP), insulin, and high molecular weight (HMW) adiponectin.

Results: Although the serum ROM level in females (347 \pm 83 Carr U) was slightly higher than in males ( $333 \pm 53$ Carr U), this was not statistically significant. In the 48 male subjects, the ROM level negatively correlated with age $(r=-0.344, p=0.0161)$, and positively correlated with the hsCRP level $(r=0.306, p=0.0338)$. In the 69 female subjects, the ROM level negatively correlated with serum creatinine $(r=-0.293, p=0.0141)$, and positively correlated with insulin $(r=0.278, p=0.0202)$, the insulin resistance index $(r=0.286, p=0.0170)$ and hsCRP levels $(r=0.487, p<0.0001)$. Stepwise multiple regression analysis revealed that serum hsCRP, creatinine, and age were independently correlated with the serum $\mathrm{ROMs}$ level $\left(\mathrm{R}^{2}=0.365 ; F\right.$ value highest for hsCRP). When the study subjects were divided into tertiles according to the ROM level, serum hsCRP was significantly different among the three groups: its level was highest in the highest tertile of ROMs $(p<0.001)$.

Conclusion: These results suggest that the serum ROM level is closely associated with serum hsCRP in Japanese adult subjects.
\end{abstract}

J Atheroscler Thromb, 2009; 16:77-82.

Key words; High-sensitivity C-reactive protein, High molecular weight adiponectin, Insulin resistance

\section{Introduction}

Since the introduction of a westernized diet and reduced physical activity in Japan, as reflected by automation and motorcars, the prevalence of lifestylerelated diseases, such as abdominal obesity, type 2 diabetes mellitus, hypertension, lipid abnormalities, and atherosclerotic disorders, has increased and become a

Address for correspondence: Hiroshi Hirose, Health Center, and Department of Internal Medicine, School of Medicine, Keio University, 35 Shinanomachi, Shinjuku-ku, Tokyo 1608582, Japan

E-mail: hhirose@hc.cc.keio.ac.jp

Received: August 19, 2008

Accepted for publication: October 16, 2008 social problem. Because these conditions often develop concurrently via visceral fat accumulation ${ }^{1)}$ and/or insulin resistance, they have been called syndrome $\mathrm{X}^{2 \text {, }}$, the deadly quartet ${ }^{3)}$, insulin resistance syndrome ${ }^{4)}$, and visceral fat syndrome ${ }^{1)}$. Recently, this syndrome has been called metabolic syndrome. The above conditions pertaining to metabolic syndrome are important risk factors for atherosclerosis and cardiovascular disease, and comorbidity of these factors is known to increase the risk of cardiovascular diseases, not additively, but rather synergistically ${ }^{5}$. Therefore, it is very important to help people recognize their importance at health checkups and improve visceral-type obesity and insulin resistance to prevent and control metabolic syndrome and/or cardiovascular diseases. 
Inflammation characterizes all phases of atherothrombosis and provides a critical pathophysiological link between plaque formation and acute rupture leading to occlusion and infarction ${ }^{6,7)}$. High-sensitivity C-reactive protein (hsCRP) is considered the best characterized of the currently available inflammatory biomarkers, and has emerged as a potential marker for cardiovascular risk ${ }^{7,8)}$. It is also known that oxidative stress is involved in the formation and progression of atherosclerosis. Recently, serum reactive oxygen metabolites (ROMs) have been reported to be a reliable biomarker to assess the effectiveness of various antioxidant treatment strategies ${ }^{7,9,10)}$.

Accumulating evidence has revealed that adipose tissue is not only an energy storage organ, but also a highly active endocrine organ ${ }^{11)}$. Moreover, it is well established that adipokines, a variety of biologically active peptides secreted from adipose tissue, play crucial roles in the pathophysiology of obesity-related complications. Among the many known adipokines, adiponectin has attracted considerable attention. Adiponectin was shown to be an anti-diabetic, anti-inflammatory and anti-atherogenic cytokine ${ }^{12,13)}$. We ${ }^{14)}$ and other groups ${ }^{15-18)}$ have reported that the serum adiponectin level correlates negatively with adiposity variables and insulin resistance. Furthermore, genetic variation of the adiponectin gene, especially the single nucleotide polymorphism (SNP) 276G > T, has been reported in Japanese subjects to relate to both type 2 diabetes mellitus ${ }^{19)}$ and carotid atherosclerosis ${ }^{20)}$. We have reported the significance of the insulin resistance index ${ }^{21)}$ and high molecular weight (HMW) adiponectin ${ }^{14,22)}$ in subjects who underwent a health checkup at our university.

Thus, the aim of this study was to clarify the relations between an oxidative stress marker, ROMs, in serum and various inflammatory and metabolic parameters in a general Japanese adult population.

\section{Subjects and Methods}

\section{Subjects}

The present study included 50 male and 73 female subjects, aged 25 to 65 years, who underwent an annual health checkup in 2007 at Keio University, Tokyo. Subjects with endocrine disease, significant renal or hepatic disease, and those receiving medication for diabetes mellitus were excluded. We also conducted a questionnaire regarding their lifestyle. This study was conducted according to the principles expressed in the Declaration of Helsinki. Informed consent was obtained from each subject after full explanation of the purpose, nature, and risk of all pro- cedures used. The protocol was approved by the ethical review committees of the Health Center and the Department of Internal Medicine, School of Medicine, Keio University, Tokyo, Japan.

\section{Measurements}

Systolic blood pressure (SBP), diastolic blood pressure (DBP), and heart rate were measured twice using an automatic electronic sphygmomanometer (BP-103i II; Nippon Colin, Komaki, Aichi Prefecture) with the subject seated after resting for at least $5 \mathrm{~min}$, as described previously ${ }^{14,21,22)}$. Height, weight, fasting plasma glucose, serum insulin, HMW adiponectin, total cholesterol, LDL-cholesterol, HDL-cholesterol and triglycerides were measured around $9 \mathrm{AM}$ after an overnight fast. Body mass index (BMI) was calculated as weight in kilograms divided by height in meters squared.

Plasma glucose and serum lipids were assayed by routine automated laboratory methods, as described previously ${ }^{14,21,22)}$. Serum insulin concentration was measured by an enzyme immunoassay, using a commercially available kit (Tosoh, Tokyo), with intra- and inter-assay coefficients of variance (CVs) of 2.9-4.6\% and $4.5-7.0 \%$, respectively ${ }^{14,22}$. The insulin resistance index was assessed by homeostasis model assessment (HOMA-IR) ${ }^{23)}$.

Serum hsCRP concentration was measured by nephelometry, a latex particle-enhanced immunoassay (N Latex CRP II; Dade Behring, Tokyo) with both intra- and inter-assay CVs of $<5.0 \%$. The assay could detect $5 \mu \mathrm{g} / \mathrm{L}$ CRP.

HMW adiponectin was measured using a commercially available kit (HMW Adiponectin ELISA Kit; Fujirebio Inc., Tokyo). This ELISA system does not need a denaturing step, and the monoclonal antibody (IH7) is reported to react specifically with the HMW form of adiponectin ${ }^{24)}$. The dilution curve was parallel to the standard curve. Intra- and inter-assay CVs were $2.4-3.0 \%$ and $4.2-5.1 \%$, respectively.

\section{Measurement of Reactive Oxygen Metabolites (ROM)}

The oxidative status was studied by measuring hydroperoxide concentration in the serum according to an automated method (d-ROMs test; Diacron srl, Italy) using a free radical elective evaluator (F.R.E.E.; Diacron srl, Italy) ${ }^{25)}$. In brief, a $20 \mu \mathrm{L}$ serum sample and $1 \mathrm{~mL}$ buffered solution (R2 kit reagent, $\mathrm{pH} 4.8$ ) were gently mixed in a cuvette, and then $10 \mu \mathrm{L}$ chromogenic substrate (R1 kit reagent) was added to the cuvette. After mixing well, the cuvette was immediately incubated in the thermostatic block of the ana- 
lyzer for $5 \mathrm{~min}$ at $37^{\circ} \mathrm{C}$, and then absorbance at 505 $\mathrm{nm}$ was recorded. Measurements are expressed as Carr Units, and it has been reported that 1 Carr U corresponds to $0.8 \mathrm{mg} / \mathrm{L} \mathrm{H}_{2} \mathrm{O}_{2}$. Reference values indicated as 'normal' by the manufacturer (Diacron srl) are from 250 to 300 Carr U; values higher than 300 Carr U suggest oxidative stress ${ }^{26,27)}$. The intra- and inter-assay CVs were $0.3-6.6 \%$ and $0.3-5.1 \%$, respectively.

\section{Statistical Analysis}

Statistical analyses were performed using the SPSS ${ }^{\circledR}$ program for Windows (version 15.0-J; SPSS Japan Inc., Tokyo). All data are expressed as the mean \pm S.D., and values of $p<0.05$ were considered significant. Significance of the mean value difference between two groups was analyzed using the MannWhitney $U$-test.

We excluded 6 subjects ( 2 males and 4 females) from the analysis, whose serum hsCRP level exceeded $500 \mu \mathrm{g} / \mathrm{L}$. Relations between ROMs and other parameters were analyzed by simple correlation and stepwise linear regression. Stepwise regression was performed in a forward direction with $F$ for the entry set to 4 . The following variables were used for the regression model: age, sex, BMI, diastolic blood pressure, HOMA-IR, serum creatinine, and hsCRP. Because serum ROMs, insulin, HOMA-IR, HMW adiponectin, triglyceride, and hsCRP levels were normally distributed after logarithmic transformation, we used logarithms of these data for the analyses.

We further divided the study subjects into tertiles based on serum ROM levels. Analysis of variance (ANOVA) followed by Scheffe's multiple comparison test was used to compare parameters among the 3 groups.

\section{Results}

The mean ROM level was $341 \pm 72$ Carr U (range: 219-601 Carr U). Although the ROM level in females $(347 \pm 83$ Carr U) was slightly higher than in males $(333 \pm 53$ Carr U), there was no statistical significance. Furthermore, there was no difference in the ROM level between the 9 smokers $(348 \pm 70$ Carr U) and 108 non-smokers (341 \pm 73 Carr U), or between the 7 diabetic subjects (309 \pm 56 Carr U) and 110 non-diabetic subjects ( $343 \pm 73$ Carr U).

We examined the correlation between ROMs and various inflammatory and metabolic parameters. In the 48 male subjects, the ROM level negatively correlated with age, and positively correlated with the hsCRP level (Table 1 and Fig. 1). In the 69 female subjects, the ROM level negatively correlated with serum creatinine, and positively correlated with insulin, HOMA-IR and hsCRP levels. There was no correlation between ROM and HMW adiponectin levels in males or females. As shown in Table 2, stepwise multiple regression analysis revealed that serum hsCRP, creatinine, and age were independently correlated with the serum ROM level.

There were gender differences in most values in Table 1, except for age, heart rate and hsCRP: although the serum hsCRP level in men tended to be higher than in women, there was no statistical significance; therefore, we divided the study subjects into tertiles according to the ROM level. The concentration of the $33 \mathrm{rd}$ and 67 th percentile was 306 and 360 Carr Units, respectively. The serum level of hsCRP was significantly different among the three groups: 19.6 $24.1 \mu \mathrm{g} / \mathrm{L}, 26.2 \pm 25.3 \mu \mathrm{g} / \mathrm{L}$, and $75.5 \pm 83.2 \mu \mathrm{g} / \mathrm{L}$ in the low, middle, and high ROM tertile groups, respectively $(p<0.001)$.

\section{Discussion}

Although hsCRP is considered the best characterized of the currently available inflammatory biomarkers ${ }^{7,8)}$, its level is often unstable and increases easily, for example, with concomitant systematic infection. Recent reports suggest that reactive oxygen metabolites (ROMs) in serum are also a reliable biomarker ${ }^{7,9,10)}$ : it has been reported that the ROMs assay was useful to assess the antioxidant treatment strategies ${ }^{10)}$ and the severity of influenza virus-associated encephalopathy ${ }^{25)}$. Furthermore, the ROM assay is relatively inexpensive and can be performed easily in 5-7 minutes.

There were no gender differences in the ROM or hsCRP levels in this study, although the serum hsCRP level in men tended to be higher than in women. It was unexpected that the serum ROM level was not correlated with adiposity or metabolic parameters. In addition, the ROM level was not different between diabetic and non-diabetic subjects, or between smokers and non-smokers. These findings, however, were considered to be due to the small number of diabetic subjects $(n=7)$ and smokers $(n=9)$ in this study. Instead, the ROM level was significantly and positively correlated with the serum hsCRP level both in males and females.

Several reports have shown a positive correlation between serum ROM and hsCRP levels in patients with coronary artery disease ${ }^{28)}$ and those undergoing hemodialysis ${ }^{29}, 30$. To our knowledge, however, there has been only one report ${ }^{31)}$ on the general population. Their subjects were relatively older (mean age $65 \pm 13$ years) in Mima City, Tokushima Prefecture, Japan. 
Table 1. Relations of reactive oxygen metabolites (ROMs) with various metabolic and inflammatory parameters in 48 male and 69 female Japanese subjects

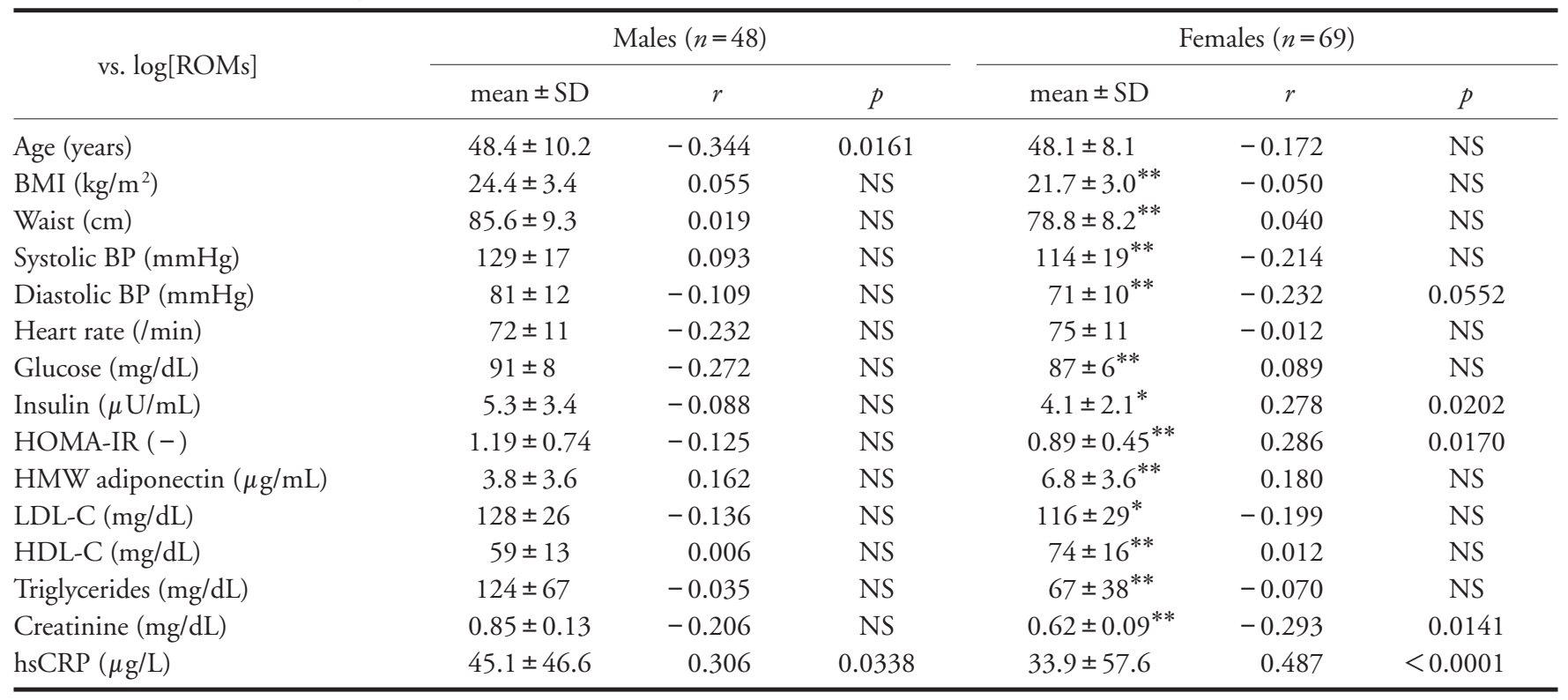

BMI: body mass index; HMW: high molecular weight; NS: $p>0.1$.

${ }^{*} p<0.05$ and ${ }^{* *} p<0.01$ vs. Male group

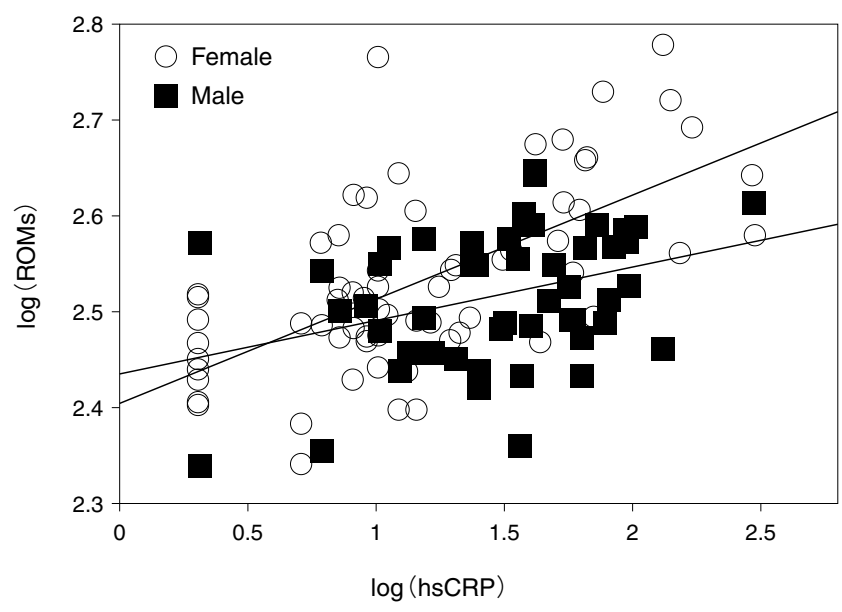

Fig. 1. Significant positive correlation between serum reactive oxygen metabolites (ROMs) and high-sensitivity C-reactive protein (hsCRP) levels in both 48 male ( and 69 female $(\bigcirc)$ subjects.

Our results in the younger age group ( $48 \pm 9$ years) in Tokyo and Yokohama in Japan were in accordance with their results ${ }^{31)}$ : ROM levels positively correlated with hsCRP levels, but not with adiponectin levels. As for the mechanisms, Fukuchi, et al. ${ }^{32)}$ reported the immunohistochemical detection of oxidative stress biomarkers, dityrosine and $N^{\varepsilon}$-(hexanoyl)lysine, and $\mathrm{C}$-reactive protein in rabbit atherosclerotic lesions.
Table 2. Stepwise multiple regression with ROMs (log) as dependent variable in 48 male and 69 female Japanese subjects

\begin{tabular}{lcrcr}
\hline \multicolumn{1}{c}{ Variable } & $\begin{array}{c}\text { Standardized } \\
\text { Regression } \\
\text { Coefficient }\end{array}$ & $F$ value & $p$ value & $\begin{array}{c}\text { Change in } \\
\mathrm{R}^{2}\end{array}$ \\
\hline hsCRP $(\log )$ & 0.528 & 48.4 & $<0.0001$ & $24.4 \%$ \\
Creatinine & -0.274 & 13.0 & $<0.0001$ & $8.4 \%$ \\
Age & -0.323 & 6.6 & $<0.0001$ & $3.7 \%$ \\
\hline
\end{tabular}

Variables are shown in order of entry.

$\mathrm{R}^{2}=36.5 \%$

Also, fluvastatin was reported to reduce cholesterol oxidation products and VCAM-1 in type 2 diabetic patients with hyperlipidemia ${ }^{33)}$, possibly through its anti-oxidative effects.

A recent study involving elderly Japanese subjects reported that a low level of HMW- adiponectin and a high level of hsCRP were synergistically associated with an increase in the number of metabolic abnormalities ${ }^{34)}$. Moreover, we have reported that the combination of hsCRP and HMW-adiponectin reflects further metabolic abnormalities compared with each alone in Japanese patients with type 2 diabetes mellitus $^{35)}$. Further studies will be needed concerning the significance of the clinical use of the ROM assay for different ages, races, and disease status. 
To summarize, in this study of subjects who underwent a health checkup, there was a significant positive correlation between serum ROM and hsCRP levels in both males and females, which suggests that ROMs may be closely associated with inflammation compared with insulin resistance or adipokine abnormalities.

\section{Acknowledgments}

This study was supported in part by a Grant-in Aid from the Ministry of Education, Culture, Sports, Science and Technology, Japan (to H.H.), and by research grants from Keio University, Tokyo (to H.H.).

\section{References}

1) Matsuzawa Y, Funahashi T, Nakamura T: Molecular mechanism of metabolic syndrome $\mathrm{X}$ : contribution of adipocytokines adipocyte-derived bioactive substances. Ann NY Acad Sci, 1999; 892:146-154

2) Reaven GM: Banting lecture 1988. Role of insulin resistance in human disease. Diabetes, 1988; 37:1595-1607

3) Kaplan NM: The deadly quartet. Upper-body obesity, glucose intolerance, hypertriglyceridemia, and hypertension. Arch Intern Med, 1989; 149:1514-1520

4) DeFronzo RA, Ferrannini E: Insulin resistance. A multifaceted syndrome responsible for NIDDM, obesity, hypertension, dyslipidemia, and atherosclerotic cardiovascular disease. Diabetes Care, 1991; 14:173-194

5) Nakamura T, Tsubono Y, Kameda-Takemura K, Funahashi T, Yamashita S, Hisamichi S, Kita T, Yamamura T, Matsuzawa Y; Group of the Research for the Association between Host Origin and Atherosclerotic Diseases under the Preventive Measure for Work-related Diseases of the Japanese Labor Ministry: Magnitude of sustained multiple risk factors for ischemic heart disease in Japanese employees: a case-control study. Jpn Circ J, 2001; 65:11-17

6) Libby P, Ridker PM, Maseri A: Inflammation and atherosclerosis. Circulation, 2002; 105:1135-1143

7) Ridker PM, Brown NJ, Vaughan DE, Harrison DG, Mehta JL: Established and emerging plasma biomarkers in the prediction of first atherothrombotic events. Circulation, 2004; 109(suppl. IV):IV6-19

8) Ridker PM: Clinical application of C-reactive protein for cardiovascular disease detection and prevention. Circulation, 2003; 107:363-369

9) Cesarone MR, Belcaro G, Carratelli M, Cornelli U, De Sanctis MT, Incandela L, Barsotti A, Terranova R, Nicolaides A: A simple test to monitor oxidative stress. Int Angiol, 1999; 18:127-130

10) Cornelli U, Terranova R, Luca S, Cornelli M, Alberti A: Bioavailability and antioxidant activity of some food supplements in men and women using the D-Roms test as a marker of oxidative stress. J Nutr, 2001; 131:3208-3211

11) Erin EK, Jeffrey SF: Adipose tissue as an endocine organ. J Clin Endoctinol Metab, 2004; 89:2548-2566
12) Yamauchi T, Kamon J, Waki H, Terauchi Y, Kubota N, Hara K, Mori Y, Ide T, Murakami K, Tsuboyama-Kasaoka N, Ezaki O, Akanuma Y, Gavrilova O, Vinson C, Reitman ML, Kagechika H, Shudo K, Yoda M, Nakano Y, Tobe K, Nagai R, Kimura S, Tomita M, Froguel P, Kadowaki T: The fat-derived hormone adiponectin reverses insulin resistance associated with both lipoatrophy and obesity. Nat Med, 2001; 7:941-946

13) Berg AH, Combs TP, Du X, Brownlee M, Scherer PE: The adipocyte-secreted protein Acrp30 enhances hepatic insulin action. Nat Med, 2001; 7:947-953

14) Yamamoto $Y$, Hirose $H$, Saito I, Tomiata $M$, Taniyama $M$, Matsubara K, Okazaki Y, Ishii T, Nishikai K, Saruta T: Correlation of the adipocyte-derived protein adiponectin with insulin resistance index and serum high-density lipoprotein-cholesterol, independent of body mass index, in the Japanese population. Clin Sci (Lond), 2002; 103:137142

15) Arita Y, Kihara S, Ouchi N, Takahashi M, Maeda K, Miyagawa J, Hotta K, Shimomura I, Nakamura T, Miyaoka K, Kuriyama H, Nishida M, Yamashita S, Okubo K, Matsubara K, Muraguchi M, Ohmoto Y, Funahashi T, Matsuzawa Y: Paradoxical decrease of an adipose-specific protein, adiponectin, in obesity. Biochem Biophys Res Commun, 1999; 257:79-83

16) Weyer C, Funahashi I, Tanaka S, Hotta K, Matsuzawa Y, Pratley RE, Tataranni PA: Hypoadiponectinemia in obesity and type 2 diabetes: close association with insulin resistance and hyperinsulinemia. J Clin Endocrinol Metab, 2001; 86:1930-1935

17) Stefan N, Vozarova B, Funahashi T, Matsuzawa Y, Weyer C, Lindsay RS, Youngren JF, Havel PJ, Pratley RE, Bogardus C, Tataranni PA: Plasma adiponectin concentration is associated with skeletal muscle insulin receptor tyrosine phosphorylation, and low plasma concentration precedes a decrease in whole-body insulin sensitivity in humans. Diabetes, 2002; 51:1884-1888

18) Tschritter O, Fritsche A, Thamer C, Haap M, Shirkavand F, Rahe S, Staiger H, Maerker E, Häring H, Stumvoll $\mathrm{M}$ : Plasma adiponectin concentrations predict insulin sensitivity of both glucose and lipid metabolism. Diabetes, 2003; 52:239-243

19) Hara K, Boutin P, Mori Y, Tobe K, Dina C, Yasuda K, Yamauchi T, Otabe S, Okada T, Eto K, Kadowaki H, Hagura R, Akanuma Y, Yazaki Y, Nagai R, Taniyama M, Matsubara K, Yoda M, Nakano Y, Tomita M, Kimura S, Ito C, Froguel P, Kadowaki T: Genetic variation in the gene encoding adiponectin is associated with an increased risk of type 2 diabetes in the Japanese population. Diabetes, 2002; 51:536-540

20) Katsuda Y, Asano A, Murase Y, Chujo D, Yagi K, Kobayashi J, Mabuchi H, Yamagishi M: Association of genetic variation of the adiponectin gene with body fat distribution and carotid atherosclerosis in Japanese obese subjects. J Atheroscler Thromb, 2007; 14:19-26

21) Hirose H, Saito I, Kawabe H, Saruta T: Insulin resistance and hypertension: seven-year follow-up study in middleaged Japanese men (the KEIO study). Hypertens Res, 2003; 26:795-800

22) Seino Y, Hirose H, Saito I, Itoh H: High molecular weight 
multimer form of adiponectin as a useful marker to evaluate insulin resistance and metabolic syndrome in Japanese men. Metabolism, 2007; 56:1493-1499

23) Matthews DR, Hosker JP, Rudenski AS, Naylor BA, Treacher DF, Turner RC: Homeostasis model assessment: insulin resistance and beta-cell function from fasting plasma glucose and insulin concentrations in man. Diabetologia, 1985; 28:412-419

24) Nakano Y, Tajima $S$, Yoshimi A, Akiyama $H$, Tsushima M, Tanioka T, Negoro T, Tomita M, Tobe T: A novel enzymelinked immunosorbent assay specific for high-molecularweight adiponectin. J Lipid Res, 2006; 47:1572-1582

25) Yamanaka G, Kawashima H, Suganami Y, Watanabe C, Watanabe Y, Miyajima T, Takekuma K, Oguchi S, Hoshika A: Diagnostic and predictive value of CSF d-ROM level in influenza virus-associated encephalopathy. J Neurol Sci, 2006; 243:71-75

26) Carratelli M, Porcaro L, Ruscica M, De Simone E, Bertelli AA, Corsi MM: Reactive oxygen metabolites and prooxidant status in children with Down's syndrome. Int J Clin Pharmacol Res, 2001; 21:79-84

27) Trotti R, Carratelli M, Barbieri M, Micieli G, Bosone D, Rondanelli M, Bo P: Oxidative stress and a thrombophilic condition in alcoholics without severe liver disease. Haematologica, 2001; 86:85-91

28) Kamezaki F, Yamashita K, Kubara T, Suzuki Y, Tanaka S, Rkouzuma R, Okazaki M, Tasaki H, Otuji Y: Derivatives of reactive oxygen metabolites correlates with highsensitivity C-reactive protein. J Atheroscler Thromb, 2008; 15:206-212

29) Filiopoulos V, Hadjiyannakos D, Metaxaki P, Sideris V, Takouli L, Anogiati A, Vlassopoulos D: Inflammation and oxidative stress in patients on hemodiafiltration.
Am J Nephrol, 2008; 28:949-957

30) Samouilidou E, Grapsa E, Karpouza A, Lagouranis A: Reactive oxygen metabolites: a link between oxidative stress and inflammation in patients on hemodialysis. Blood Purif, 2007; 25:175-178

31) Sakane N, Fujiwara S, Sano Y, Domichi M, Tsuzaki K, Matsuoka Y, Hamada T, Saiga K, Kotani K: Oxidative stress, inflammation, and atherosclerotic changes in retinal arteries in the Japanese population; results from the Mima study. Endocrine J, 2008; 55:485-488

32) Fukuchi $Y$, Miura $Y$, Nabeno $Y$, Kato $Y$, Osawa T, Naito M: Immunohistochemical detection of oxidative stress biomarkers, dityrosine and $\mathrm{N}$ (hexanoyl)-lysine, and Creactive protein in rabbit atherosclerotic lesions. J Atheroscler Thromb, 2008; 15:185-192

33) Guan JZ, Murakami H, Yamato K, Tanabe J, Matsui J, Tamasawa N, Suda T: Effects of fluvastatin in type 2 diabetic patients with hyperlipidemia: reduction in cholesterol oxidation products and VCAM-1. J Atheroscler Thromb, 2004; 11:56-61

34) Tabara $Y$, Osawa $H$, Kawamoto R, Tachibana-Iimori R, Yamamoto M, Nakura J, Miki T, Makino H, Kohara K: Reduced high-molecular weight adiponectin and elevated hsCRP are synergistic risk factors for metabolic syndrome in a large scale middle-aged to elderly population: the Shimanami Health Promoting Program Study. J Clin Endocrinol Metab, 2008; 93:715-722

35) Saisho Y, Hirose H, Yamamoto Y, Nakatani H, Itoh H: Combination of C-reactive protein and high molecular weight (HMW)-adiponectin reflects further metabolic abnormalities compared with each of them alone in Japanese type 2 diabetic subjects. Endocr J, 2008; 55:331-338 